\title{
Someone Is Going To Pay for This
}

serve on the university committee on the library at Rice University where we consider, among other things, the allocation of resources. Libraries have not been immune to the

broad budget cuts at universities in recent years. Considering that a significant portion of a library budget goes toward journal subscriptions, and that those rates have risen for most publishers, we often discuss ways to get the broadest possible journal access for our faculty. At times, we also wonder why subscription rates have risen so rapidly. It seems like electronic publication could offer efficiencies that might lower the cost of producing journals; however, electronic publication comes with entirely new infrastructure needs, such as programming instead of typesetting, servers instead of distribution houses, and people with technical skills that are valuable to other industries. A detailed analysis might actually show that publishing electronically is, in fact, more expensive than print. But in addition to the everyday delivery of manuscripts from author to reader, publishers provide an important service: the evaluation and peer review of scientific research. Each manuscript is screened by editors, the top fraction are sent for peer review to multiple experts in the field, the responses are read and analyzed, decisions are made, and sometimes, the entire process repeats. In terms of both logistics and intellectual effort, this feat does not come cheap and cannot be scaled up via assembly line. As research grows worldwide, so will manuscript submissions and so will the costs associated with their evaluation.

Where should that cost fall? This question has not escaped our committee's deliberations. Rice is currently rewriting its open access policies with an aim to make all faculty research publicly available. The open access (OA) movement has been developing since papers were first put online but gained a significant presence when the $\mathrm{NIH}$ mandated in 2008 that all peer-reviewed manuscripts by $\mathrm{NIH}$ funded investigators be made publicly available. ${ }^{1}$ Open access proponents argue that having free access to scien-

The open access movement has been developing since papers were first put online but gained a significant presence when the NIH mandated in 2008 that all peer-reviewed manuscripts by NIHfunded investigators be made publicly available. tific results will maximize the benefit of scientific research to society, but the issue has raised a complex debate over the impact of freely available articles on scientific publishing. ${ }^{2}$ Two well-known OA publishers, Public Library of Science (PLOS) and BioMed Central, cover their costs by charging substantial publication fees to the manuscript authors. Publication fees are not new and have long been included in research budgets. However, if the entire cost of scientific publishing were to follow this model, publication costs would certainly become onerous for researchers. Institutions could cover the publication fees, but the funds would likely come from the same limited budgets that are currently used to subscribe to journals. In the end, similar money would change between similar hands according to different formulas. However, there would be one significant and potentially damaging differenceresearchers would have to rely on institutional resources to submit a manuscript. The ability to submit a manuscript should not be tied to a researcher's previous success or funding levels. Those factors already drive enough aspects of academic research.

The current widely practiced mode of self-archiving and author distribution of reprints seems to satisfy most aspirations of the OA movement. Publication databases can be searched by the public or by researchers, even in resource-poor environments, and a simple e-mail request is usually all that is required to receive an "electronic reprint" from the corresponding author. ${ }^{3}$ Subscription publishers are also making efforts to satisfy OA needs. ACS Publications has programs to make articles open access and to distribute reprints. ${ }^{4-6}$ While there are still specialized $O A$ issues regarding data mining and other modern research methods, it does not seem that broad federal mandates or drastic changes to scientific publishing are needed. A variety of publication models are available, and publishers on all

Published online June 26, 2012

$10.1021 / \mathrm{nn} 3025755$

() 2012 American Chemical Society 


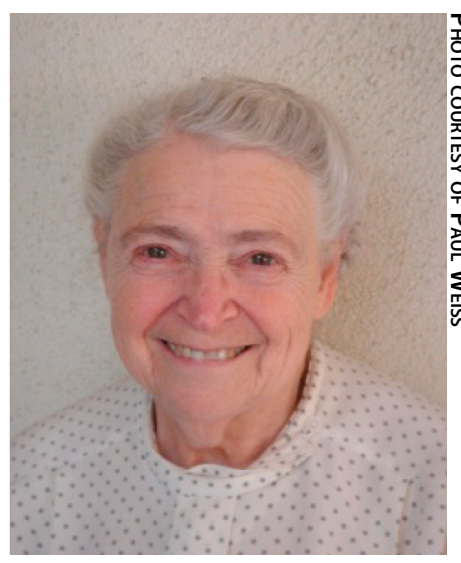

Prof. Mildred Dresselhaus of MIT has won the 2012 Kavli Prize in Nanoscience for her work on carbon nanomaterials. sides of the $\mathrm{OA}$ issue are constantly taking advantage of new technologies to be sure that publicly funded science continues to serve the public.

Finally, please join us in congratulating editorial advisory board member and frequent contributor Prof. Mildred Dresselhaus of MIT on winning the 2012 Kavli Prize in Nanoscience for her pioneering work on carbon nanomaterials, to be awarded by King Harald $\mathrm{V}$ of Norway this fall in Oslo. ${ }^{7-9}$ An ACS Nano Conversation with Prof. Dresselhaus was published in 2009 and has been made freely available, along with all other Conversations in the journal. ${ }^{7}$

Disclosure: Views expressed in this editorial are those of the author and not necessarily the views of the American Chemical Society.

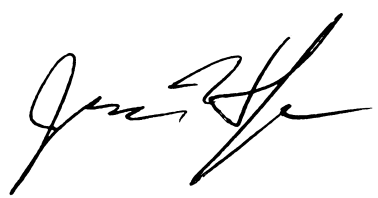

Jason H. Hafner

Associate Editor

\section{REFERENCES AND NOTES}

1. Laakso, M.; Welling, P.; Bukvova, H.; Nyman, L.; Björk, B.-C.; Hedlund, T. The Development of Open Access Journal Publishing from 1993 to 2009. PLoS ONE 2011, 6, e20961.

2. Gugliotta, G. Gulf on Open Access to Federally Financed Research. The New York Times, Feb. 27, 2012. http://www.nytimes.com/2012/02/28/science/a-wide-gulf-on-open-access-to-federally-financed-research. html.

3. Weiss, P. S. Who Are Corresponding Authors? ACS Nano 2012, 6, 2861-2861.

4. ACS AuthorChoice (ACS Publications). http://pubs.acs.org/page/policy/authorchoice/index.html.

5. ACS Articles on Request Policy (ACS Publications). http://pubs.acs.org/page/policy/articlesonrequest/ index.html.

6. ACS Nano Information for Authors. http://pubs.acs.org/paragonplus/submission/ancac3/ancac3 authguide.pdf.

7. Weiss, P. S. A Conversation with Prof. Mildred Dresselhaus: A Career in Carbon Nanomaterials. ACS Nano 2009, 3, 2434-2440

8. Dresselhaus, M. S.; Araujo, P. T. Perspectives on the 2010 Nobel Prize in Physics for Graphene. ACS Nano 2010, 4, 6297-6302.

9. Fujisawa, K.; Komiyama, K.; Muramatsu, H.; Shimamoto, D.; Tojo, T.; Kim, Y. A.; Hayashi, T.; Endo, M. Oshida, K.; Terrones, M. Chirality-Dependent Transport in Double-Walled Carbon Nanotube Assemblies: The Role of Inner Tubes. ACS Nano 2011, 5, 7547-7554. 